\title{
PROSPEK PENGEMBANGAN MINAPOLITAN DI KABUPATEN SITUBONDO
}

Prospect of Minapolitan Development in Situbondo Regency

\author{
Yuli Wibowo $^{1) *}$, Nidya Shara Mahardika ${ }^{1)}$, Lia Sumi Karmila ${ }^{1)}$ \\ ${ }^{1)}$ Program Studi Teknologi Industri Pertanian, Fakultas Teknologi Pertanian, Universitas Jember \\ Jalan Kalimantan No. 37 Kampus Tegal Boto, Jember 68121 \\ *Korespondensi Penulis: yuliwibowo.ftp@unej.ac.id
}

\begin{abstract}
The Government of Situbondo Regency has implemented an agropolitan program in its region since 2013 to develop the potential of fisheries and marine resources. However, the program has not been able to develop as expected and still lacks the impact. This study aimed to determine the prospects for the development of the Minapolitan program in Situbondo Regency. The results of this study were expected to provide guidelines for the development of the Minapolitan program in Situbondo Regency. This study used a prospective analysis method. Method of minapolitan development strategy formulation used Analytical Hierarchy Process (AHP). This research produced scenarios that might occur in the future. These scenarios could serve as a guideline for the preparation of the minapolitan development strategy in Situbondo Regency. The results of the study showed that there were four scenarios will occur in the future, namely the optimistic developing scenario, the pessimistic developing scenario, there was still hope scenario and alert scenario. Based on discussions with experts, the most likely scenario to occur were an optimistic developing scenario and there was still hope scenario. Based on the scenarios that were most likely to occur, the strategy that can be applied for the development of Minapolitan in Situbondo Regency based on AHP method was to provide assistance and facilitate access to technology, markets, and capital.
\end{abstract}

Keywords: analytical hierarchy process, minapolitan, prospective analysis

\section{PENDAHULUAN}

Jawa Timur merupakan provinsi yang memiliki kawasan laut hampir empat kali luas daratannya dengan panjang garis pantai kurang lebih $2.916 \mathrm{~km}$. Provinsi Jawa Timur memiliki kawasan laut yang cukup luas mencapai $208.097 \mathrm{~km}^{2}$ meliputi Laut Jawa, Selat Madura, Selat Bali dan Samudera Indonesia (PDSI, 2013). Provinsi Jawa Timur tidak hanya luas dari segi wilayah, tetapi juga kaya akan sumberdaya alam sehingga dapat menjadi daya dukung pembangunan wilayah. Jawa Timur merupakan salah satu provinsi penghasil produksi perikanan terbesar di Indonesia. Jumlah produksi perikanan di provinsi ini pada tahun 2017 tercatat sebesar 1,8 juta ton (KKP, 2018).

Salah satu wilayah di Provinsi Jawa Timur yang memiliki potensi kelautan dan perikanan adalah Kabupaten Situbondo.
Kabupaten Situbondo terletak di pesisir pantai utara Provinsi Jawa Timur. Kabupaten Situbondo memiliki luas wilayah laut sebesar 1.142,4 km (BPS, 2019). Secara geografis, wilayah perairan Potensi Perikanan di Kabupaten Situbondo terkonsentrasi di wilayah pantai dengan usaha-usaha penangkapan ikan di laut, budidaya tambak, budidaya air tawar, budidaya air laut, pembenihan, dan usaha pengolahan (Ismail, 2013).

Dalam rangka memanfaatkan potensi perikanan di Kabupaten Situbondo secara optimal yang dikaitkan dengan kesejahteran nelayan, maka diperlukan program blue economy atau industrialisasi usaha perikanan dari hulu hingga hilir yang dapat menjamin usaha perikanan berbasis pada pengembangan kawasan (Ghalidza, 2020), salah satunya adalah pengembangan minapolitan (Wibowo et al., 2015). 
$\begin{array}{ccr}\text { Minapolitan merupakan } & \begin{array}{r}\text { upaya } \\ \text { kerangka }\end{array}\end{array}$ pengembangan wilayah (Fatmawati et al., 2018). Peraturan Menteri Kelautan dan Perikanan RI Nomor PER.12/MEN/2010 tentang minapolitan menjelaskan bahwa minapolitan adalah sebuah konsepsi pembangunan ekonomi kelautan dan perikanan berbasis kawasan berdasarkan prinsip-prinsip terintegrasi, efisiensi, berkualitas dan percepatan. Kawasan minapolitan adalah suatu bagian wilayah yang memiliki fungsi utama ekonomi yang terdiri dari sentra produksi, pengolahan, pemasaran komoditas perikanan, pelayanan jasa, dan/atau kegiatan pendukung lainnya (PERMEN, 2010). Adanya pembangunan kawasan diharapkan akan dapat meningkatkan perekonomian masyarakat di sekitar kawasan (KKP, 2013).

Kabupaten Situbondo merupakan salah satu wilayah di Provinsi Jawa Timur yang ditetapkan menjadi kawasan minapolitan percontohan pada tahun 2013 (KKP, 2013). Sebagai tindak lanjut penetapan Kabupaten Situbondo sebagai kawasan minapolitan percontohan, maka dikeluarkan Surat Keputusan Bupati Situbondo No:118/516/P/004.2/2013 tentang penetapan lokasi minapolitan di Kabupaten Situbondo. Lokasi minapolitan di Kabupaten Situbondo meliputi Kecamatan Banyuputih, Mangaran, Panarukan, Bungatan, Kapongan, dan Besuki (Perbub, 2013).

Pengembangan minapolitan di Kabupaten Situbondo terus dikembangkan oleh pemerintah setempat, hal tersebut tercatat di dalam Rencana Program Investasi Jangka Menengah (RPIJM) Program Minapolitan di Kabupaten Situbondo pada tahun 2014 dan Rencana Strategis 2016-2021 Dinas Perikanan Kabupaten Situbondo (Dinas Perikanan, 2017). Hingga saat ini, program minapolitan di Kabupaten Situbondo masih belum terlihat perkembangannya secara signifikan. Berdasarkan kondisi tersebut, maka penelitian yang bertujuan untuk mengetahui prospek pengembangan minapolitan di Kabupaten Situbondo di masa yang akan datang, serta merumuskan strategi pengembangannya.

\section{METODE PENELITIAN}

\section{Alat dan Bahan}

Alat yang digunakan yaitu laptop, buku catatan dan kuesioner. Bahan yang digunakan yaitu data primer yang diperoleh dari hasil wawancara dan data sekunder yang diperoleh dari hasil telaah pustaka dan data pada instansi terkait.

\section{Metode Pengumpulan Data}

Jenis data yang digunakan adalah data sekunder dan data primer. Data sekunder diperoleh dari informasi dan data Badan Perencanaan Pembangunan Daerah (BAPPEDA), Dinas Kelautan dan Perikanan Kabupaten Situbondo, jurnaljurnal hasil penelitian yang terkait dan beberapa dokumen. Data primer diperoleh dari responden (pakar) melalui wawancara dan pemberian kuesioner. Observasi lapangan dilakukan di kawasan Minapolitan Kabupaten Situbondo.

\section{Metode Pengolahan Data}

Prospek Pengembangan Minapolitan

Metode yang digunakan untuk merumuskan prospek pengembangan minapolitan di Kabupaten Situbondo adalah metode analisis prospektif. Analisis prospektif dapat digunakan untuk formulasi strategi pengembangan kawasan perikanan (Wardono et al., 2019).

Analisis prospektif adalah teknik menentukan strategi yang akan terjadi di masa yang akan datang berdasarkan kondisi saat ini (Fadhil et al., 2018). Metode ini sangat membantu untuk menyiapkan kebijakan strategis dan memperkirakan apakah perubahan perlu dilakukan di masa yang akan datang (Godet, 2000). Analisis prospektif 
merupakan alat untuk merumuskan strategi di masa depan (Fierro, 2015).

Metode analisis prospektif bertujuan untuk menghasilkan beberapa skenario yang mungkin terjadi pada pengembangan minapolitan di Kabupaten Situbondo. Tahapan dalam analisis prospektif yaitu: (Hardjomidjojo, 2002; Fadhil et al., 2018):

1. Mendefinikasikan tujuan yang dikaji secara spesifik.

2. Identifikasi faktor-faktor yang berpengaruh dalam tujuan.

3. Analisis pengaruh antar kriteria. Pedoman penilaian analisis prospektif disajikan pada Tabel 1.

Tabel 1. Pedoman penilaian analisis prospektif

\begin{tabular}{cc}
\hline Skor & Pengaruh \\
\hline 0 & Tidak ada pengaruh \\
1 & Berpengaruh kecil \\
2 & Berpengaruh sedang \\
3 & Berpengaruh sangat kuat \\
\hline
\end{tabular}

Sumber: Benjumea-Arias et al. (2016)

Hasil matriks gabungan pendapat pakar diolah dengan perangkat lunak analisis prospektif. Hasil perhitungan divisualisasikan dalam diagram pengaruh dan ketergantungan antar faktor sehingga dihasilkan faktor kunci pada Gambar 1.

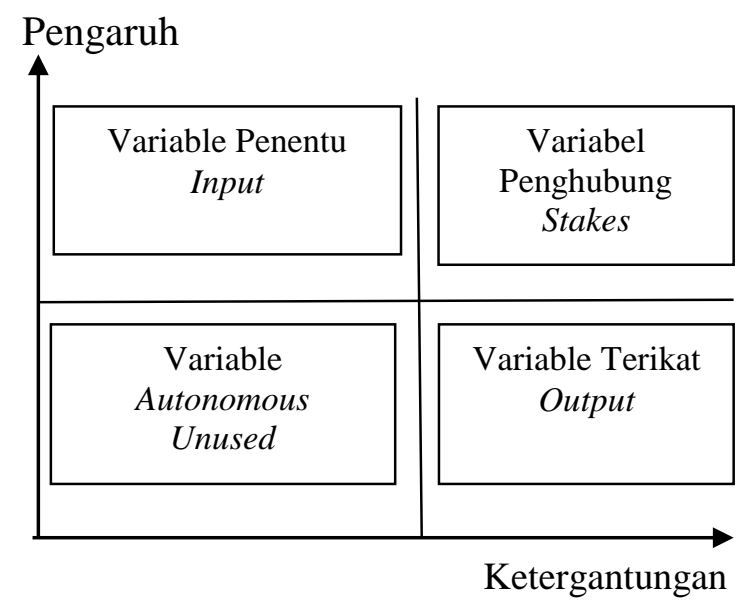

Gambar 1. Diagram pengaruh dan ketergantungan system (Hardjomidjojo, 2002)
4. Penyusunan keadaan yang mungkin terjadi (state) pada faktor. Berdasarkan faktor dominan yang diperoleh pada tahap 3, disusun keadaan yang mungkin terjadi di masa depan. Setiap faktor boleh memiliki lebih dari satu keadaan, dengan ketentuan keadaan harus memiliki peluang sangat besar untuk terjadi (bukan khayalan) dalam suatu waktu di masa yang akan datang.

5. Penyusunan skenario. Skenario memuat seluruh faktor, tetapi untuk setiap faktor hanya memuat satu keadaan dan tidak memasukkan pasangan keadaan yang mutual incompatible.

\section{Strategi Pengembangan Minapolitan}

Perumusan strategi pengembangan minapolitan di Kabupaten Situbondo menggunakan teknik Analytical Hierarchy Process (AHP) (Saaty, 1987).

1. Membentuk matriks perbandingan berpasangan. Tabel matriks perbandingan berpasangan ditunjukkan pada Tabel 2.

Tabel 2. Matriks perbandingan berpasangan

\begin{tabular}{ccccc}
\hline C & A1 & A2 & $\ldots \ldots$ & Aj \\
\hline A1 & a11 & a12 & $\ldots$ & A1j \\
A2 & a21 & a22 &.. & a2j \\
$\ldots$ & $\ldots$ & $\ldots$ & $\ldots$ & \\
Ai & Ai1 & Ai2 & $\ldots$ & Aij \\
\hline
\end{tabular}

Keterangan :

$\mathrm{Ai}, \mathrm{Aj}=$ elemen ke-i atau ke-j terkait dengan kriteria

$\mathrm{i}, \mathrm{j}=1,2, \ldots \ldots, \mathrm{n}$ adalah indek elemen yang terdapat pada tingkat yang sama dan secara bersama-sama terkait dengan kriteria.

Aij = angka yang diberikan dengan membandingkan elemen ke-i dengan elemen ke-j sehubungan dengan kriteria.

2. Melakukan perbandingan berpasangan. Skala dasar perbandingan ditunjukkan pada Tabel 3. 
Tabel 3. Skala dasar perbandingan

\begin{tabular}{cc}
\hline $\begin{array}{c}\text { Tingkat } \\
\text { Kepentingan }\end{array}$ & Definisi \\
\hline 1 & Sama pentingnya \\
3 & Sedikit lebih penting \\
5 & Lebih penting \\
7 & Sangat penting \\
9 & Mutlak lebih penting \\
$2,4,6,8$ & Nilai-nilai tengah diantara \\
& dua pendapat yang \\
& berdampingan \\
Kebalikan & Jika elemen $i$ memiliki salah \\
& satu angka diatas ketika \\
& dibandingkan elemen $j$ maka $j$ \\
& memiliki kebalikannya ketika \\
& dibanding elemen $i$ \\
\hline
\end{tabular}

Sumber: Saaty (1987)

3. Penilaian oleh multiexpert. Penilaian multiexpert adalah penilaian yang dilakukan lebih dari satu pakar, dimana nantinya akan menghasilkan pendapat yang berbeda satu sama lain. Rumus rataan geometri dapat dituliskan sebagai berikut:

$\mathrm{GM}=\sqrt[n]{\mathrm{a} 1 \times \mathrm{a} 2 \ldots \ldots \mathrm{xan}}$

Keterangan:

GM: Geometrik Mean (rata-rata geometric)

a1 : hasil penilaian dari pakar pertama

a2 : hasil penilaian dari pakar kedua

n : jumlah pakar

4. Menetapkan prioritas (Synthesis of Priority). Model matematika yang digunakan mengacu pada, yaitu: (Marimin, 2004)

$$
e P_{1}=\frac{\sqrt[n]{\prod_{j=1}^{n} a_{i j}}}{\sum_{i=1}^{n} \prod_{j=1}^{n}}
$$

Keterangan:

eVPi = elemen vektor prioritas ke-i

aij = penilaian berpasangan elemen ke-i terhadap elemen ke-j
Model matematika dalam penyusunan matriks pendapat gabungan sebagai berikut:

$\mathrm{g}(\mathrm{ij})=\sqrt[m]{\prod_{k=1}^{m}}\left(\boldsymbol{a}_{i j}\right)_{k}$

Dimana:

$$
\begin{array}{ll}
\mathrm{g}(\mathrm{ij})= & \text { elemen MPG baris ke-i } \\
& \text { kolom ke- } \mathrm{j} \\
\mathrm{m} & =\text { jumlah responden (pakar) } \\
(\text { aij)k }= & \text { elemen baris ke-i kolom } \\
& \text { ke-j dari MPI ke-k } \\
\mathrm{X} & =\begin{array}{c}
\text { perkalian dari elemen } \mathrm{k}=1 \\
\end{array} \\
& \text { sampai k-m }
\end{array}
$$

5. Uji konsistensi indeks dan rasio. Rumus penentuan konsistensi adalah sebagai berikut:

a) Perhitungan nilai eigen maksimum $(\lambda \max )$

$\mathrm{VA}=$ aij $\mathrm{x} \mathrm{VP}$

$\mathrm{VB}=\mathrm{VA} / \mathrm{VP}$

Keterangan:

$\mathrm{VA}=\mathrm{VB}=$ vektor antara

b)Perhitungan niali CI dan CR

$\mathrm{CI}=\lambda \max -n / n-1$

Keterangan:

$C I=$ Rasio penyimpangan (deviasi) konsistensi (consistency indeks)

$\lambda \max =$ Nilai eigen terbesar dari matriks berordo $n$

$n=$ Orde Matriks

Batas ketidak konsistenan (inconsistency) yang telah ditetapkan oleh (Saaty, 1987) ditentukan dengan menggunakan Rasio Konsistensi (CR). Rasio Konsistensi dapat dirumuskan pada rumus sebagai berikut:

$$
\begin{aligned}
& \mathrm{CI}=C I / R I \\
& \text { Keterangan : } \\
& \mathrm{CR}=\text { Rasio Konsistensi } \\
& \mathrm{R} \mathrm{I}=\text { Indeks Random }
\end{aligned}
$$

Nilai random indeks bisa di dapatkan dari Tabel 4. 
Tabel 4. Nilai random indeks (RI)

\begin{tabular}{cc}
\hline $\mathrm{N}$ & $\mathrm{R} 1$ \\
\hline 1 & 0,00 \\
2 & 0,00 \\
3 & 0,58 \\
4 & 0,90 \\
5 & 1,12 \\
6 & 1,24 \\
7 & 1,32 \\
8 & 1,41 \\
9 & 1,45 \\
10 & 1,48 \\
\hline
\end{tabular}

Sumber: Saaty (1987)

6. Sintesis prioritas (Composite Priority). Model matematika yang digunakan adalah sebagai berikut:

$\mathrm{NP}_{\mathrm{pq}}=\sum_{t=1}^{s} N P H p q(t, q-1) x N P T t(q-1)$

$$
\begin{aligned}
\text { Keterangan: } & \\
\mathrm{NP}_{\mathrm{pq}}= & \text { nilai prioritas pengaruh } \\
& \text { elemen ke-p pada } \\
& \text { tingkat ke-q terhadap } \\
& \text { sasaran utama } \\
= & \text { nilai prioritas elemen } \\
& \text { ke-p pada tingkat ke-q } \\
\mathrm{NPH}_{\mathrm{pq}} & \text { nilai prioritas pengaruh } \\
& \text { elemen ke-t tingkat q-1 }
\end{aligned}
$$

\section{HASIL DAN PEMBAHASAN}

\section{Gambaran Umum Wilayah}

Kabupaten Situbondo merupakan salah satu Kabupaten di Jawa Timur yang letaknya berada di ujung timur Pulau Jawa bagian utara. Wilayah Kabupaten Situbondo sebagian besar memiliki laut yang cukup luas. Kabupaten Situbondo memiliki potensi kelautan dan perikanan yang besar meliputi pembenihan, budidaya air payau, budidaya laut, dan air tawar, penangkapan ikan dan pengolahan hasil perikanan (Dinas Perikanan, 2017). Jumlah produksi perikanan tangkap tahun 2018 tercatat sebesar 14.241,7 ton, sementara pada tahun yang sama jumlah produksi budidaya air kolam sebesar 243,68 ton, budidaya tambak $8.882,95$ ton, dan karamba jaring apung mencapai 93,12 ton (BPS, 2019).

Pemanfaatan sumberdaya perikanan terkait dengan pemanfaatan potensi kelautan dan perikanan yang dimanfaatkan oleh masyarakat. Pengelolaan dan pemanfaatan sumberdaya perikanan di Kabupaten Situbondo pada dasarnya memiliki tujuan untuk meningkatkan kesejahteraan seluruh masyarakat Situbondo (Ismail, 2013).

Kabupaten Situbondo merupakan salah satu lokasi pengembangan minapolitan percontohan berbasis perikanan budidaya tahun 2013 (KKP, 2013). Potensi kelautan dan perikanan yang menunjang pengembangan minapolitan di Kabupaten Situbondo meliputi: (i) usaha penangkapan ikan di laut; (ii) usaha budidaya berupa tambak, kolam, keramba jaring apung, rumput laut, benih air laut, dan benih air tawar; dan (iii) usaha pengolahan yang terdiri dari pengolahan ikan asin/kering, ikan pindang, kerupuk, dan lain-lain.

Lokasi minapolitan di Kabupaten Situbondo, meliputi:

1. Kecamatan Banyuputih dan Mangaran sebagai sentra budidaya udang.

2. Kecamatan Panarukan sebagai sentra penangkapan ikan dan budidaya kerapu.

3. Kecamatan Bungatan sebagai sentra pembenihan ikan dan udang

4. Kecamatan Kapongan sentra budidaya ikan air tawar

5. Kecamatan Besuki merupakan sentra budidaya rumput laut.

Implementasi kebijakan terkait dengan pengembangan minapolitan di Kabupaten Situbondo tertuang dalam Rencana Program Investasi Jangka Menengah (RPIJM) Program Minapolitan di Kabupaten Situbondo pada tahun 2014. Pada Rencana Strategis 2016-2021 Dinas Perikanan Kabupaten Situbondo, pengembangan kawasan minapolitan masih menjadi isu strategis yang perlu diperhatikan atau dikedepankan dalam 
perencanaan pembangunan karena dampak yang signifikan di masa datang (Dinas Perikanan, 2017). Pada renstra disampaikan pula bahwa pembangunan kawasan minapolitan diarahkan melalui industrialisasi perikanan berdasarkan konsep blue economy, sebagaimana disampaikan oleh (Ghalidza, 2020).

Pengembangan minapolitan terus dilakukan oleh pemerintah Kabupaten Situbondo melalui Dinas Perikanan sebagai leading sector, salah satunya yaitu memperkuat kelembagaan dan sumberdaya manusia. Kelembagaan lokal yang ada di daerah pesisir mempunyai peran penting dalam mendorong aktivitas ekonomi masyarakat. Proses pengembangan masyarakat pesisir yang dilakukan tidak didasarkan pada rencana standar yang sama atau seragam untuk seluruh wilayah, namun didasarkan pada kondisi dan potensi sumberdaya alam, SDM, dan kegiatan usaha yang ada.

Faktor-Faktor yang Berpengaruh Terhadap Pengembangan Minapolitan Di Kabupaten Situbondo

Tahap awal dalam analisis prospektif yaitu menentukan faktor-faktor yang berpengaruh terhadap pengembangan minapolitan. Menurut Zali et al. (2015), tujuan dalam analisis struktural adalah menemukan faktor-faktor yang berpengaruh yang disebut dengan faktor kunci.

Faktor tersebut diperoleh dari studi pustaka, wawancara dan pendapat dari pakar. Faktor-faktor yang teridentifikasi adalah sebagai berikut:

1. Lokasi

2. Perkembangan penduduk

3. Sumberdaya manusia

4. Sumberdaya finansial

5. Ketersediaan sarana dan prasarana

6. Ketersediaan teknologi dan pengembangannya

7. Kebijakan pemerintah
8. Infrastruktur

9. Sinergisme pembangunan kawasan minapolitan dan pengelolaan BUMDES

10. Indikator keberhasilan minapolitan

11. Arah kebijakan

12. Komitmen pemerintah daerah

13. Dukungan tokoh masyarakat

14. Kelembagaan lokal

15. Dukungan tokoh masyarakat

Faktor Kunci Pengembangan Minapolitan di Kabupaten Situbondo

Berdasarkan 15 faktor yang sudah terindentifikasi, faktor tersebut dilakukan penilaian antar faktor. Penilaian tersebut dilakukan oleh pakar yang sudah ditentukan. Faktor yang mempengaruhi pengembangan minapolitan Kabupaten Situbondo ditunjukkan pada Gambar 2.

Berdasarkan Gambar 2 diperoleh faktor kunci yang sangat mempengaruhi pengembangan minapolitan Kabupaten Situbondo. Faktor kunci berada pada kuadran input dan stakes, yaitu:

a. Sumberdaya Manusia

Sumberdaya manusia merupakan kemampuan SDM dalam mengelola minapolitan. Sumberdaya manusia yang berkaitan langsung dengan minapolitan adalah nelayan dan masyarakat yang tinggal di sekitar pantai. Keberhasilan minapolitan sangat ditentukan oleh kebaradaan SDM nelayan dalam menjalankan usahanya. Jumlah nelayan dan jumlah penduduk di wilayah pesisir Kabupaten Situbondo ditunjukkan pada Tabel 5 dan Tabel 6.

Tabel 5. Jumlah nelayan di Kabupaten Situbondo

\begin{tabular}{ccccc}
\hline Nelayan & \multicolumn{4}{c}{ Tahun } \\
\cline { 2 - 5 } & 2014 & 2015 & 2016 & 2017 \\
\hline Pemilik & 2733 & 1305 & 1447 & 1447 \\
Pendega & 5656 & 8051 & 9243 & 9243 \\
Sambilan & 2037 & 2037 & 2178 & 2178 \\
\hline Sumber: BPS (2019) & & &
\end{tabular}




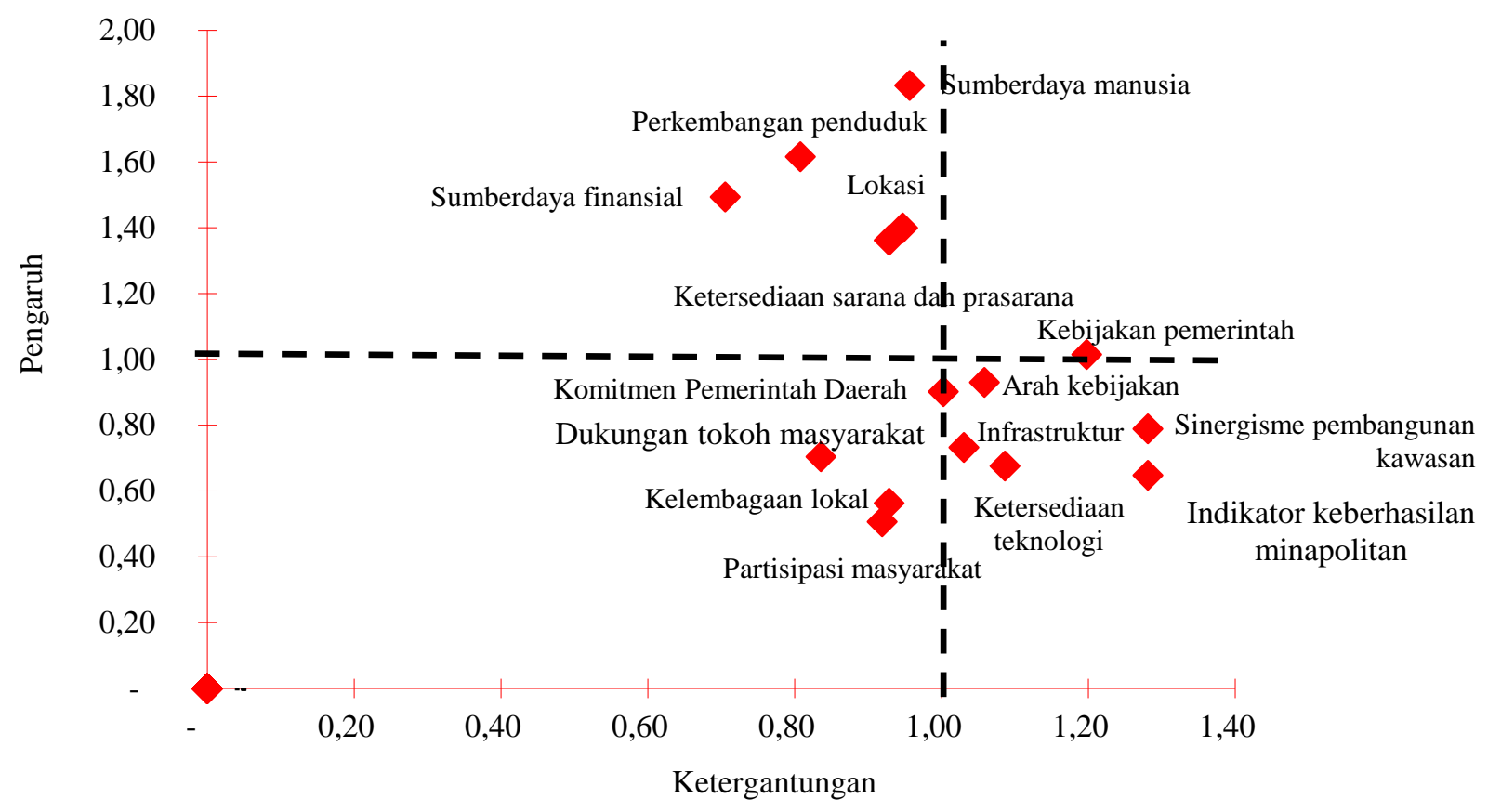

Gambar 2. Faktor yang mempengaruhi pengembangan minapolitan Kabupaten Situbondo

Tabel 6. Jumlah penduduk Kabupaten Situbondo tahun 2017

\begin{tabular}{llccc}
\hline & & \multicolumn{3}{c}{ Jenis Kelamin } \\
\cline { 3 - 5 } & Kecamatan & $\begin{array}{c}\text { Laki- } \\
\text { Laki }\end{array}$ & $\begin{array}{c}\text { Perem- } \\
\text { puan }\end{array}$ & Jumlah \\
\hline 1 & Sumbermalang & 12.845 & 13.541 & 26.386 \\
2 & Jatibanteng & 10.710 & 11.526 & 22.236 \\
3 & Banyuglugur & 11.533 & 12.264 & 23.797 \\
4 & Besuki & 31.789 & 33.362 & 65.151 \\
5 & Suboh & 13.291 & 13.977 & 27.268 \\
6 & Mlandingan & 10.856 & 11.547 & 22.403 \\
7 & Bungatan & 12.196 & 13.183 & 25.379 \\
8 & Kendit & 13.934 & 14.657 & 28.591 \\
9 & Panarukan & 27.899 & 28.906 & 56.805 \\
10 & Situbondo & 23.479 & 24.733 & 48.212 \\
11 & Mangaran & 16.057 & 17.164 & 33.221 \\
12 & Panji & 35.503 & 37.620 & 73.123 \\
13 & Kapongan & 18.734 & 19.870 & 38.604 \\
14 & Arjasa & 20.058 & 20.734 & 40.792 \\
15 & Jangkar & 18.178 & 19.025 & 37.203 \\
16 & Asembagus & 23.525 & 24.536 & 48.061 \\
17 & Banyuputih & 29.524 & 29.947 & 59.471 \\
\hline & Situbondo & $\mathbf{3 3 0 . 1 1 1}$ & $\mathbf{3 4 6 . 5 9 2}$ & $\mathbf{6 7 6 . 7 0 3}$ \\
\hline
\end{tabular}

Sumber: BPS (2019)

Berdasarkan Tabel 5 dan Tabel 6, proporsi jumlah nelayan terhadap jumlah penduduk di kawasan minapolitan
(Kecamatan Besuki, Bungatan, Panarukan, Mangaran, Kapongan dan Banyuputih) masih tergolong rendah, yaitu hanya sebesar 4,62\%. Namun demikian, para nelayan ini diharapkan dapat menjadi motor penggerak (local champion) bagi berkembangnya minapolitan di Kabupaten Situbondo. Upaya yang dapat dilakukan adalah terus mengembangkan kemampuan dalam berusaha di bidang usaha perikanan.

b. Perkembangan Penduduk

Penduduk memiliki pengaruh cukup signifikan bagi berkembangnya minapolitan di Kabupaten Situbondo. Jumlah penduduk yang besar menunjukkan tersedianya SDM yang cukup khususnya dalam mengelola kawasan minapolitan. Berkembangnya minapolitan diharapkan pula dapat menjadi pengungkit bagi tumbuhnya industri terkait (forward linkages), yang pada akhirnya dapat memacu penyerapan jumlah tenaga kerja. Selain itu, jumlah penduduk yang besar juga dapat menjadi pasar yang pasti (captive market) bagi 
minapolitan dan industri terkait. Ketersediaan dan kejelasan pasar merupakan salah satu kunci keberhasilan dalam pengembangan minapolitan di Kabupaten Situbondo. Pada tahun 2017, jumlah penduduk Kabupaten Situbondo mencapai 676.703 orang. Penduduk Kabupaten Situbondo naik sebesar 0,05\% jika dibandingkan dengan tahun 2016.

c. Sumberdaya Finansial

Sumberdaya finansial merupakan kemampuan finansial dalam mendukung keberadaan minapolitan atau sumber biaya yang didapatkan untuk mendukung minapolitan. Jumlah biaya yang diperlukan untuk mengembangkan kawasan minapolitan di Kabupaten Situbondo tentu sangat besar, tidak hanya untuk membiayai berbagai infrastruktur yang dibutuhkan untuk pengembangan kawasan, tetapi juga dukungan permodalan bagi para pelaku usaha di kawasan minapolitan. Oleh karena itu, sumberdaya finansial tidak hanya bersumber dari APBD Pemerintah Kabupaten Situbondo, tetapi juga perlu didukung oleh sumber dana lain yang berasal dari pihak perbankan atau lainnya.

\section{d. Lokasi}

Pengembangan minapolitan harus dilakukan di lokasi yang strategis. Secara geografis, Kabupaten Situbondo memiliki laut yang cukup luas. Hampir semua kecamatan, atau 14 kecamatan di wilayah Kabupaten Situbondo memiliki pantai, hanya 3 kecamatan saja yang tidak memiliki pantai. Hal ini menunjukkan bahwa secara lokasi, wilayah Kabupaten Situbondo telah memiliki potensi bagi pengembangan minapolitan. Kecamatankecamatan yang dianggap paling strategis untuk pengembangan minapolitan di Kabupaten Situbondo adalah Kecamatan Besuki, Bungatan, Panarukan, Mangaran, Kapongan dan Banyuputih, sesuai dengan Keputusan Bupati Situbondo Nomor 118/516/P/004.2/2013 tentang penetapan lokasi minapolitan di Kabupaten Situbondo (Perbub, 2013). e. Ketersediaan Sarana dan Prasarana

Sarana dan prasarana merupakan kebutuhan penunjang dan penting bagi keberhasilan usaha di kawasan minapolitan. Oleh karena itu, keberadaannya sangat diperlukan di kawasan ini. Ketersediaan sarana prasarana yang ada di Kabupaten Situbondo menurut Dinas Perikanan Kabupaten Situbondo meliputi tempat pelelangan ikan, cold strorage, penjemuran ikan, gudang dan docking bengkel. Sarana dan prasarana tersebut harus tersedia, khususnya di kecamatankecamatan yang telah ditetapkan sebagai kawasan minapolitan di Kabupaten Situbondo.

\section{f. Kebijakan Pemerintah}

Indikator kebijakan pemerintah dimaksudkan sebagai ukuran dari kualitas administrasi pemerintahan daerah, khususnya dalam rangka menyediakan infrastruktur fisik dan peraturan-peraturan daerah. Pada penelitian ini, kebijakan pemerintah merupakan semua dasar hukum (law enforcement) yang berkaitan dengan pengaturan kawasan minapolitan yang diterbitkan oleh pemerintah pusat hingga pemerintah kabupaten, yaitu UU, PP, Kepmen, Perda, SK, dan lain-lain.

\section{Skenario Pengembangan Minapolitan}

Skenario merupakan gambaran situasi masa depan yang didasari dari situasi saat ini. Skenario terdiri dari beberapa asumsi yang masuk akal, berdasarkan pada faktor-faktor yang dapat dijelaskan (Godet, 2000). Skenario merupakan persepsi lingkungan masa depan (Mckiernan, 2017).

Skenario pengembangan minapolitan disusun berdasarkan keadaan (state) yang akan terjadi masa yang akan datang pada setiap faktor kunci yang teridentifikasi. Pemetaan keadaan faktor-faktor pengembangan minapolitan di Kabupaten Situbondo ditunjukkan pada Tabel 7.

Berdasarkan Tabel 7, melalui diskusi bersama pakar, maka telah 
dirumuskan beberapa skenario yang mungkin akan terjadi terkait dengan keberadaan program minapolitan di masa yang akan datang. Menurut Wibowo, (2010), skenario merupakan gabungan setiap faktor pada berbagai keadaan yang akan terjadi di masa yang akan datang.

Skenario yang terbentuk ditunjukkan pada Tabel 8.

Tabel 8. Skenario pengembangan minapolitan

\begin{tabular}{ccc}
\hline No & \multicolumn{1}{c}{ Skenario } & \multicolumn{1}{c}{ Keadaan } \\
\hline 1 & $\begin{array}{l}\text { Optimis } \\
\text { berkembang }\end{array}$ & 1A-2A-3A-4A-5A-6A \\
2 & $\begin{array}{l}\text { Pesimis } \\
\text { berkembang }\end{array}$ & 1C/1D-2C-3B-4B-5C-6C \\
3 & $\begin{array}{l}\text { Masih ada } \\
\text { harapan }\end{array}$ & 1A-2B/2C-3B-4B-5B-6B \\
4 & Waspada & 1B-2B/2C-3B-4B-5B-6B \\
\hline
\end{tabular}

Tabel 8 menunjukkan ada 4 (empat) skenario yang mungkin akan terjadi pada kawasan minapolitan di Kabupaten Situbondo. Skenario-skenario tersebut meliputi:

1. Skenario optimis

Skenario optimis merupakan skenario yang mungkin terjadi di masa yang akan datang jika semua keadaan mendukung terhadap pengembangan minapolitan.

2. Skenario pesimis

Skenario pesimis merupakan skenario yang mungkin terjadi di masa yang akan datang, akan tetapi skenario ini merupakan skenario yang tidak diinginkan di masa yang akan datang. Skenario ini mungkin terjadi jika semua keadaan tidak mendukung terhadap pengembangan minapolitan.

Tabel 7. Pemetaan keadaan faktor-faktor pengembangan minapolitan

\begin{tabular}{|c|c|c|c|c|}
\hline Faktor kunci & A & $\mathrm{B}$ & $\mathrm{C}$ & $\mathrm{D}$ \\
\hline \multirow{2}{*}{$\begin{array}{c}\text { Kebijakan } \\
\text { pemerintah }\end{array}$} & $1 \mathrm{~A}$ & $1 \mathrm{~B}$ & $1 \mathrm{C}$ & $1 \mathrm{D}$ \\
\hline & $\begin{array}{c}\text { Meningkat } \\
\text { Mendukung untuk } \\
\text { pengembangan perikanan di } \\
\text { Situbondo dan meningkatkan } \\
\text { nilai tambah. } \\
\end{array}$ & Tetap & $\begin{array}{c}\text { Menurun } \\
\text { Kurang mendukung, karena } \\
\text { masih focus ke program } \\
\text { lainnya }\end{array}$ & $\begin{array}{l}\text { Sudah tidak ada } \\
\text { keberlanjutan } \\
\text { Program } \\
\text { Minapolitan di } \\
\text { Kab. Situbondo } \\
\end{array}$ \\
\hline \multirow{2}{*}{$\begin{array}{l}\text { Ketersediaan } \\
\text { sarana } \\
\text { prasarana }\end{array}$} & $2 \mathrm{~A}$ & $2 \mathrm{~B}$ & $2 \mathrm{C}$ & $2 \mathrm{D}$ \\
\hline & $\begin{array}{l}\text { Meningkat, sesuai dengan } \\
\text { kebutuhan teknologi untuk } \\
\text { pengembangan usaha yang } \\
\text { mendukung Minapolitan. }\end{array}$ & Tetap & $\begin{array}{l}\text { Menurun, karena usaha yang } \\
\text { mendukung Minapolitan } \\
\text { mulai menurun produksinya }\end{array}$ & \\
\hline \multirow{2}{*}{$\begin{array}{c}\text { Sumberdaya } \\
\text { Manusia }\end{array}$} & 3 A & $3 \mathbf{B}$ & $3 \mathrm{C}$ & 3 D \\
\hline & $\begin{array}{l}\text { Berkembang dengan adanya } \\
\text { penguasaan teknologi dan } \\
\text { tingkat pendidikan }\end{array}$ & Tetap & $\begin{array}{l}\text { Menurun akibat kurangnya } \\
\text { penguasaan IPTEK dan } \\
\text { minimnya pendidikan. }\end{array}$ & \\
\hline \multirow{2}{*}{$\begin{array}{l}\text { Perkembangan } \\
\text { penduduk }\end{array}$} & $\mathbf{4 A}$ & $4 \mathrm{~B}$ & $4 \mathrm{C}$ & $4 \mathrm{D}$ \\
\hline & $\begin{array}{c}\text { Semakin meningkat dengan } \\
\text { bertambahnya jumlah } \\
\text { penduduk }\end{array}$ & Tetap & & \\
\hline \multirow{2}{*}{$\begin{array}{l}\text { Sumberdaya } \\
\text { finansial }\end{array}$} & $5 \mathrm{~A}$ & $5 \mathrm{~B}$ & $5 \mathrm{C}$ & $5 \mathrm{D}$ \\
\hline & $\begin{array}{c}\text { Cukup tersedia dengan } \\
\text { dukungan pemerintah daerah } \\
\text { dan sumberdaya finansial } \\
\text { lainnya. }\end{array}$ & $\begin{array}{l}\text { Tetap, } \\
\text { tidak ada } \\
\text { perkem- } \\
\text { bangan } \\
\end{array}$ & $\begin{array}{c}\text { Menurun karena tidak } \\
\text { adanya kecukupan modal } \\
\text { usaha. }\end{array}$ & \\
\hline \multirow[t]{2}{*}{ Lokasi } & $6 \mathrm{~A}$ & $6 \mathrm{~B}$ & $6 \mathrm{C}$ & 6 D \\
\hline & $\begin{array}{l}\text { Ketersediaan lokasi usaha } \\
\text { perikanan semakin } \\
\text { meningkat sehingga kawasan } \\
\text { minapolitan semakin luas }\end{array}$ & Tetap & $\begin{array}{c}\text { Menurun, lahan } \\
\text { dimanfaatkan untuk usaha } \\
\text { non perikanan }\end{array}$ & \\
\hline
\end{tabular}


3. Skenario masih ada harapan

Skenario masih ada harapan merupakan skenario yang mungkin terjadi jika semua keadaan tetap seperti sekarang namun dalam hal ini pemerintah masih memberikan dukungan terhadap keberlanjutan program pengembangan minapolitan.

4. Skenario waspada

Skenario waspada merupakan skenario yang mungkin terjadi jika semua keadaan tetap tidak ada perubahan seperti sekarang atau program pengembangan minapolitan jalan di tempat.

\section{Penyusunan Strategi Pengembangan Minapolitan di Kabupaten Situbondo}

Skenario dapat digambarkan sebagai instrumen strategis bagi pembuat keputusan untuk perencanaan dan pemrograman, mengurangi tingkat ketidakpastian dan inkonsistensi (Godet, 2000). Adanya skenario akan memungkinkan untuk melakukan tindakan atau strategi yang lebih baik (Mckiernan, 2017).

Penyusunan strategi pengembangan minapolitan di Kabupaten Situbondo didasarkan pada skenario yang telah disusun sebelumnya. Strategi yang dihasilkan dapat menjadi pedoman (guidelines) dalam mengambil tindakan strategis dalam pengembangan minapolitan di Kabupaten Situbondo.

Berdasarkan diskusi dengan pakar, dari keempat skenario yang mungkin terjadi di masa yang akan datang tersebut, maka hanya ada 2 (dua) skenario yang paling mungkin terjadi sehingga dapat diketahui prospek pengembangannya, yaitu skenario optimis berkembang dan skenario masih ada harapan.

Berdasarkan skenario yang paling mungkin terjadi di masa yang akan datang, maka perlu disusun strategi yang sesuai, yaitu strategi yang mendukung agar skenario optimis dapat terjadi dan skenario masih ada harapan yang memungkinkan untuk dikembangkan. Perumusan strategi pengembangan minapolitan menggunakan metode AHP yang dikembangkan oleh Saaty (1987).

Penentuan strategi pengembangan minapolitan di Kabupaten Situbondo memerlukan beberapa kriteria, meliputi:

a. Biaya

Kriteria biaya menujukkan total biaya yang dibutuhkan dan yang harus dipertimbangkan untuk kebutuhan dalam merealisasikan strategi dalam pengembangan minapolitan. Semakin kecil biaya yang diperlukan, semakin baik. b. Ketercapaian Tujuan / Efektivitas

Kriteria ini menunjukkan sejauh mana strategi yang akan dipilih dapat mencapai tujuannya atau efektif, yaitu berkembangnya minapolitan di Kabupaten Situbondo.

c. Kemudahan Operasional Strategi

Strategi yang baik adalah strategi yang secara operasional mudah untuk dilakukan. Semakin mudah strategi dioperasionalkan maka akan semakin baik. d. Risiko

Kriteria risiko menunjukkan sejauh mana strategi yang dipilih mempunyai risiko yang berdampak kurang baik bagi pengembangan minapolitan. Semakin kecil risiko strategi, semakin baik.

e. Kemanfaatan

Kriteria kemanfaatan menunjukkan sejauh mana strategi yang dipilih dapat memberikan manfaat untuk bagi pengembangan minapolitan di Kabupaten Situbondo.

\section{Strategi Skenario Optimis}

Skenario optimis merupakan skenario yang mungkin terjadi jika semua keadaan mendukung terhadap pengembangan minapolitan. Strategi optimis berkembang difokuskan untuk mewujudkan agar skenario ini dapat terjadi. Hasil perumusan strategi pada skenario optimis ditunjukkan pada Gambar 3.

Gambar 3 menunjukkan terdapat 4 (empat) alternatif strategi yang dapat 


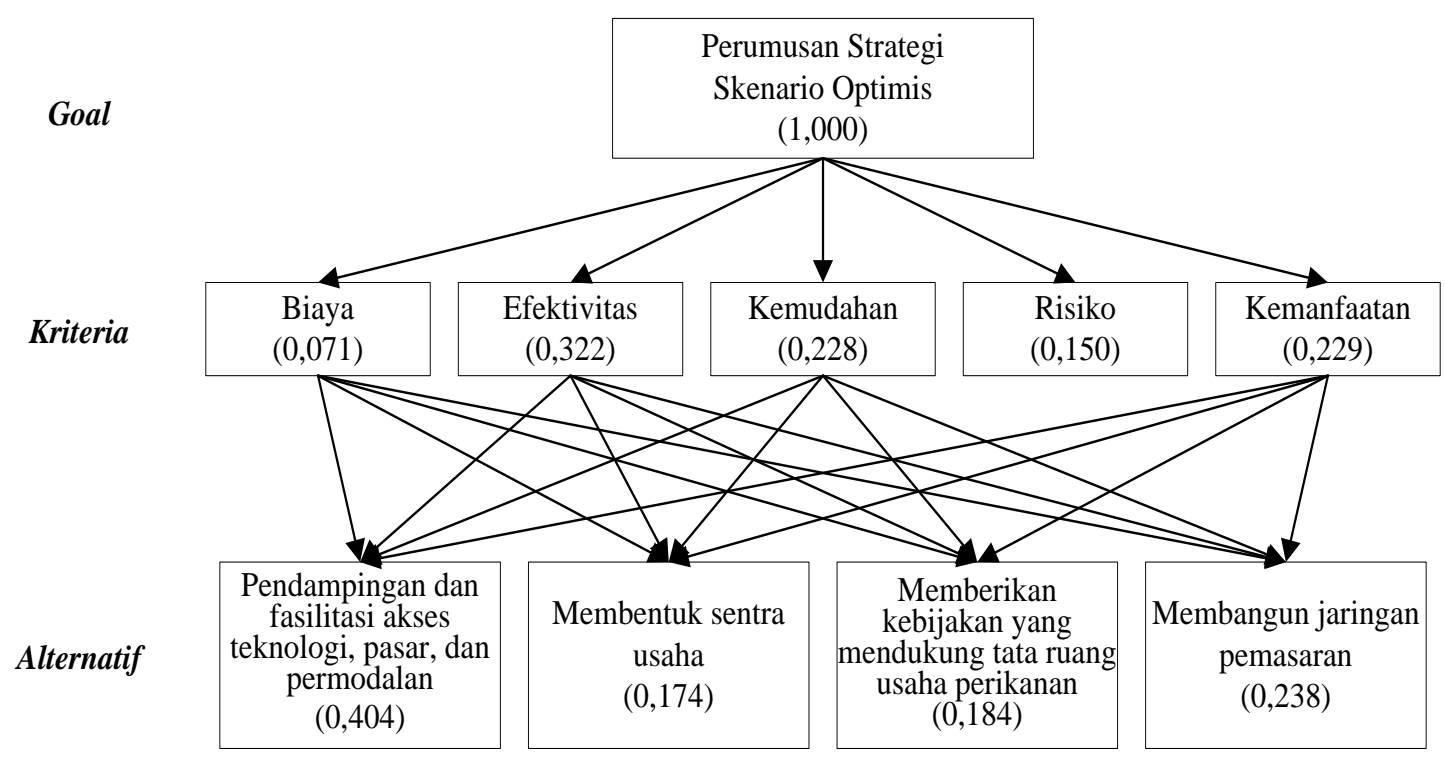

Gambar 3. Struktur hirarki pemilihan alternatif strategi skenario optimis

dilakukan untuk mewujudkan skenario optimis. Alternatif-alternatif strategi tersebut meliputi: (i) pendampingan dan fasilitasi akses teknologi, pasar, dan permodalan; (ii) membentuk sentra usaha; (iii) memberikan kebijakan yang mendukung tata ruang usaha perikanan; dan (iv) membangun jaringan pemasaran.

Hasil analisis AHP menunjukkan bahwa prioritas strategi yang dapat dilakukan pada skenario optimis adalah strategi pendampingan serta fasilitasi akses teknologi, pasar, dan permodalan. Strategi ini terpilih dengan memiliki bobot tertinggi $(0,404)$. Hal-hal yang perlu diperhatikan untuk mewujudkan strategi optimis yaitu pendampingan fasilitasi akses teknologi, pasar dan permodalan dengan cara: (i) membentuk pasar untuk hasil perikanan, pasar untuk sarana perikanan (pakan, obat-obatan, dan lainlain), dan pasar untuk jasa pelayanan termasuk pasar lelang; (ii) mempermudah perijinan untuk peminjaman modal kepada lembaga keuangan (perbankan dan non perbankan) sebagai sumber modal untuk kegiatan perikanan; dan (iii) melakukan bimbingan teknologi untuk mengembangkan teknologi tepat guna yang cocok untuk daerah kawasan minapolitan.

\section{Strategi Skenario Masih Ada Harapan}

Skenario masih ada harapan merupakan skenario yang mungkin terjadi jika semua keadaan tetap seperti sekarang namun dalam hal ini Pemerintah Kabupaten Situbondo masih memberikan dukungan terhadap keberlanjutan program pengembangan minapolitan. Hasil perumusan strategi pada skenario masih ada harapan ditunjukkan pada Gambar 4.

Ada 4 (empat) alternatif strategi yang dapat dilakukan untuk mewujudkan skenario optimis (Gambar 4). Alternatifalternatif strategi tersebut meliputi: (i) memberikan kebijakan yang mendukung kepastian tata ruang usaha perikanan; (ii) meningkatkan ketersediaan sarana prasarana yang dibutuhkan untuk pengembangan program; (iii) meningkatkan kualitas SDM; dan (iv) pendampingan dan fasilitasi akses teknologi, pasar, dan permodalan. 


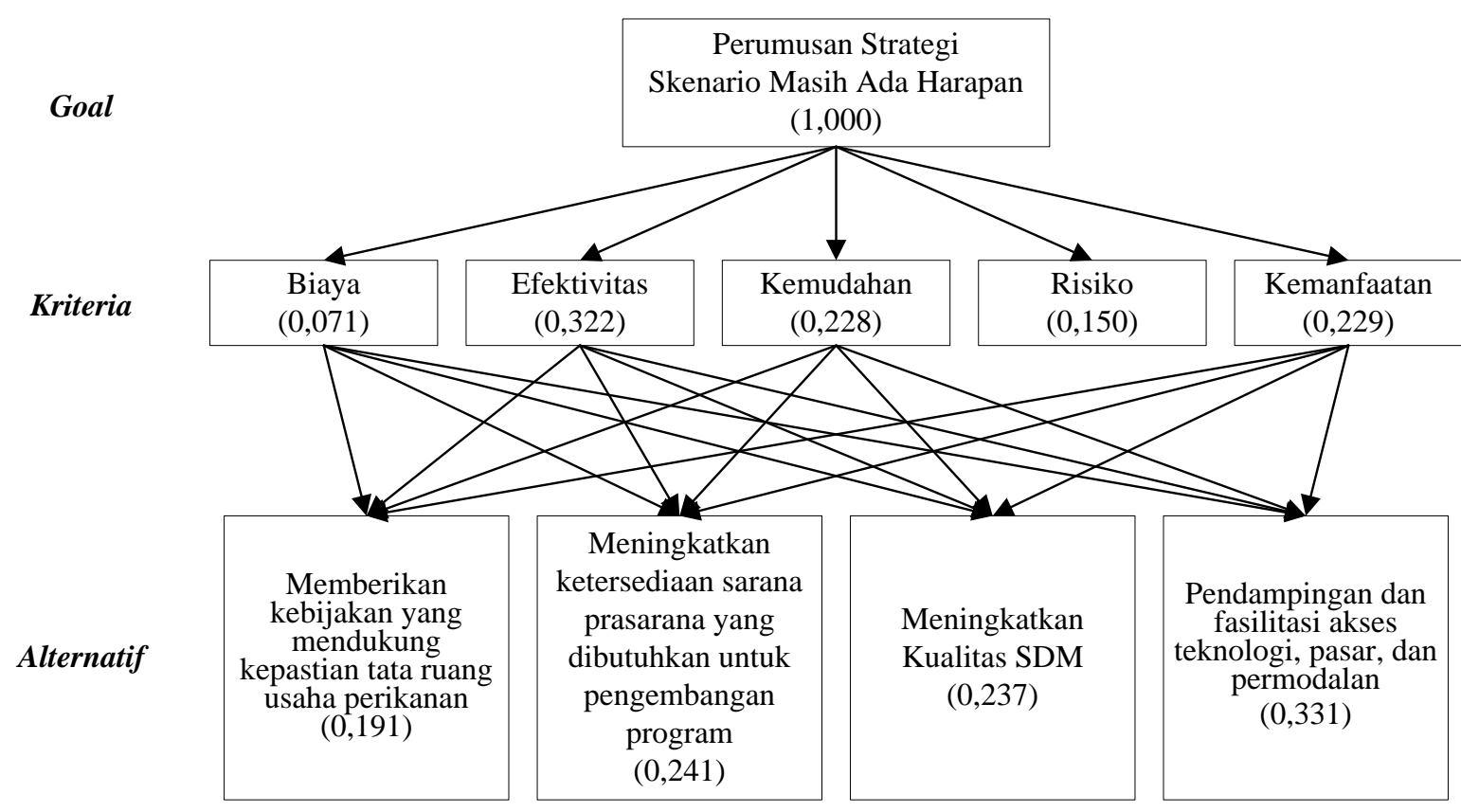

Gambar 4. Struktur hirarki pemilihan alternatif strategi skenario masih ada harapan

Hasil analisis AHP menunjukkan bahwa prioritas strategi yang dapat dilakukan pada scenario masih ada harapan yaitu melakukan pendampingan serta fasilitasi akses teknologi, pasar, dan permodalan. Strategi ini terpilih dengan memiliki bobot tertinggi $(0,331)$. Strategi yang diperoleh antara skenario optimis dan skenario masih ada harapan ternyata sama yaitu melakukan pendampingan dan fasilitasi akses teknologi, pasar, dan permodalan. Alternatif strategi tersebut yang dapat digunakan untuk pengembangan minapolitan di Kabupaten Situbondo. Strategi tersebut juga sesuai dengan syarat-syarat kawasan minapolitan menurut pedoman umum pengembangan kawasan minapolitan yang dikeluarkan oleh Kementerian Kelautan dan Perikanan, dalam syarat-syarat tersebut kawasan minapolitan harus memiliki pasar, lembaga keuangan, serta penyuluhan dan bimbingan teknologi (KKP, 2013).

\section{KESIMPULAN}

Pengembangan minapolitan di Kabupaten Situbondo masih mempunyai prospek yang cukup menjanjikan berdasarkan skenario-skenario yang mungkin akan terjadi masa yang akan datang. Minapolitan di Kabupaten Situbondo akan optimis berkembang jika Pemerintah Kabupaten Situbondo dapat memfokuskan program-programnya pada pengembangan minapolitan. Dukungan pemerintah daerah memiliki peran penting dalam pengembangan minapolitan. Fokus program yang perlu dilakukan dalam pengembangan minapolitan di Kabupaten Situbondo adalah melakukan pendampingan dan fasilitasi akses teknologi, pasar, dan permodalan.

\section{DAFTAR PUSTAKA}

Benjumea-Arias, M., Castañeda, L., ValenciaArias, A. 2016. Structural analysis of strategic variables through MICMAC use: Case study. Mediterranean Journal of Social Sciences MCSER Publishing, 7 (4): 2039-9340.

BPS. 2019. Kabupaten Situbondo Dalam Angka 2019. Badan Pusat Statistik Kabupaten Situbondo.

Dinas Perikanan. 2017. RENSTRA 2016-2021. Dinas Perikanan Kabupaten Situbondo. 
Fadhil, R., Maarif, M.S., Bantacut, T., Hermawan, A. 2018. A prospective strategy for institutional development of gayo coffee agroindustry in aceh province, indonesia. Bulgarian Journal of Agricultural Science, 24 (6): 959966.

Fatmawati, Ikawati, Amri, E. 2018. Strategi pengembangan kawasan minapolitan di Kecamatan Pamboang Kabupaten Majene dalam konsep pengembangan wilayah. Plano Madani, 7: 37-45.

Fierro, G.G. 2015. Strategic prospective methodology to explore sustainable futures. Journal of Modern Accounting and Auditing, 11 (11): 606-614.

Ghalidza, N.M.B. 2020. Konsep blue economy terhadap pembangunan ekonomi di Indonesia. Jurnal Ekonomi dan Bisnis, 22 (1): 27-31.

Godet, M. 2000. Fore front: how to be rigorous with scenario planning. The Journal of Futures Studies, Strategic Thinking and Policy, 02 (01): 30.

Hardjomidjojo, H. 2002. Strategi Pengembangan Usaha Kecil Menengah. Departemen Teknologi Industri Pertanian, Fakultas Teknologi Pertanian, IPB, 1-15.

Ismail, M. 2013. Implementasi program pelestarian Kabupaten Situbondo. Jurnal Review Politik, 03 (02): 168-189.

KKP. 2013. Pengembangan Kawasan Minapolitan. Kementerian Kelautan dan Perikanan RI.

KKP. 2018. Kelautan dan Perikanan Dalam Angka 2018. Pusat Data, Statistik dan Informasi Kementerian Kelautan dan Perikanan

Mckiernan, P. 2017. Prospective thinking: Scenario planning meets neuroscience. Technological Forecasting and Social Change, 124: 66-76.

PDSI. 2013. Profil Kelautan dan Perikanan Provinsi Jawa Timur untuk Mendukung Industrialisasi KP. Pusat Data Statistik dan Informasi Kementerian Kelautan dan Perikanan.
Perbub. 2013. Surat Keputusan Bupati Situbondo No:118/516/P/004.2/2013 tentang penetapan lokasi minapolitan di Kabupaten Situbondo.

PERMEN. 2010. Peraturan Menteri Kelautan dan Perikanan Republik Indonesia Nomor PER.12/MEN/2010. 10 p.

Saaty, R.W. 1987. The analytic hierarchy process-what it is and how it is used. Mathematical Modelling, 9 (3-5): 161176.

Wardono, B., Muhartono, R., Hikmayani, Y., Apriliani, T., Hikmah, H. 2019. Analisis prospektif peran aktor dalam strategi formulasi pembangunan daerah di Kabupaten Natuna. Jurnal Sosial Ekonomi Kelautan dan Perikanan, 14 (2): 79-195.

Wibowo, A. B., Anggoro, S., Yulianto, B. 2015. Status keberlanjutan dimensi ekologi dalam pengembangan kawasan minapolitan berkelanjutan berbasis perikanan budidaya air tawar di Kabupaten Magelang. Indonesian Journal of Fisheries Science and Technology (IJFST), 10 (2): 107-113.

Wibowo, Y. 2010. Analisis prospektif strategi pengembangan daya saing perusahaan daerah perkebunan. Agrointek, 4 (2): 104-113.

Zali, N., Rabbani, T., Motti, V.V. 2015. Application of prospective structural analysis for identification of strategic variables in the future development of Baneh City in Iran. European Spatial Research and Policy, 22 (1): 153-171. 